\title{
Eosinophils: Offenders or General Bystanders in Allergic Airway Disease and Pulmonary Immunity?
}

\author{
Praveen Akuthota ${ }^{a, b}$ Jason J. Xenakis ${ }^{b}$ Peter F. Weller ${ }^{b, c}$ \\ Divisions of a Pulmonary, Critical Care and Sleep Medicine, ${ }^{\mathrm{b}}$ Allergy and Inflammation, and ${ }^{\mathrm{C}}$ Infectious Diseases, \\ Department of Medicine, Beth Israel Deaconess Medical Center, Harvard Medical School, Boston, Mass., USA
}

\section{Key Words}

Eosinophils $\cdot$ Asthma $\cdot$ Allergy $\cdot$ Pulmonary immunity

\begin{abstract}
Eosinophils have long been noted to be present in asthma and other forms of pulmonary inflammation, but whether they act as true offenders or merely as bystanders has been a point of uncertainty. However, in recent years, there has been increasing evidence suggesting that eosinophils are not passive cells in the respiratory system, acting only as markers of allergic inflammation. This review discusses key evidence from animal models and human clinical trials that support the importance of eosinophils as active and necessary, rather than passive and unnecessary, to the pathogenesis of allergic airway disease. Analyses that are supportive of important immunoregulatory roles of eosinophils in allergic pulmonary inflammation are also reviewed. Data indicating that eosinophils contribute to viral, bacterial, and mycobacterial defense and clearance are detailed. Continually increasing evidence has supported a new conception of eosinophils as being multifaceted immune cells with complex interactions with other immune cells and their local environment.

Copyright ๑ 2011 S. Karger AG, Basel
\end{abstract}

\section{Introduction}

Despite decades of study since Ehrlich first identified eosinophils in the 1870s, the role of eosinophils in health and disease remains enigmatic [1]. Similarly, mechanisms of eosinophilic inflammation and the purpose of eosinophilic infiltration into tissues continue to be a relatively poorly understood aspect of immunology. The role of eosinophils in the respiratory system is emblematic of the controversies surrounding this cell. Eosinophils have long been noted to be present in asthma and other forms of pulmonary inflammation, but whether they act as true offenders or merely as bystanders has been a point of uncertainty. However, in recent years, there has been increasing evidence suggesting that eosinophils are not passive cells in the respiratory system, acting only as markers of allergic inflammation. In fact, regarding eosinophils as only end-stage effectors is insufficient as a model [2]. Studies of eosinophils in animal models of allergic airway inflammation as well as in clinical studies of human asthma have converged to the point where eosinophils must be considered to be active cytotoxic and immunomodulatory entities. This review will discuss key evidence from animal models and human clinical trials

\section{KARGER}

Fax +41613061234

E-Mail karger@karger.ch

www.karger.com
(C) 2011 S. Karger AG, Basel

Accessible online at: www.karger.com/jin
Dr. Peter F. Weller

Department of Medicine

Beth Israel Deaconess Medical Center, CLS 943

330 Brookline Avenue, Boston, MA 02215 (USA)

Tel. +1 617735 4110, Fax +1 617735 4115, E-Mail pweller@ bidmc.harvard.edu 
that support the importance of eosinophils as active and necessary, rather than passive and unnecessary, to the pathogenesis of allergic airway disease. Analyses that are supportive of important immunoregulatory roles of eosinophils in allergic pulmonary inflammation will also be reviewed. Though eosinophils have not been traditionally thought to play a role in pulmonary immunity against respiratory pathogens, their status in pulmonary immunity is evolving to encompass a potentially new role as cells important to antimicrobial defense against a variety of pathogens. Data indicating that eosinophils contribute to viral, bacterial, and mycobacterial defense and clearance will be detailed.

\section{Eosinophils in Allergic Airway Inflammation: Animal Models}

While the true effector function of eosinophils in allergic airway inflammation has been an area of ongoing controversy, a series of murine studies has established that eosinophils are more than bystander cells in asthma models. Two reports appeared in 2004, describing the phenotypes of 2 different strains of eosinophil-deficient mice in ovalbumin challenge asthma models $[3,4]$. Humbles et al. [3] reported that eosinophil-deficient $\Delta \mathrm{dbl}$ GATA mice had decreased airway remodeling as assayed by collagen deposition compared to wild-type animals. These mice are selectively deficient in eosinophils due to the deletion of a high-affinity GATA binding site in the GATA-1 promoter. While mice that are completely deficient in GATA-1 demonstrate embryonic lethality with erythrocyte and megakaryocyte deficiencies, those with the deletion of the dbl GATA high-affinity site are viable mice with no hematopoietic deficiencies other than the loss of eosinophils $[5,6]$. In the study of $\Delta \mathrm{dbl} \mathrm{GATA} \mathrm{mice}$ by Humbles and colleagues [3], airway hyperresponsiveness and other measures of obstructive physiology were not significantly different between $\Delta$ dbl GATA mice and wild-type controls [3]. Lee et al. [4] described that a second murine strain lacking eosinophils known as PHIL mice also had attenuated responses to allergic airway challenge. PHIL mice are selectively deficient in eosinophils due to the expression of diphtheria toxin A in eosinophil lineage cells under the control of the promoter for eosinophil peroxidase. Unlike $\Delta \mathrm{dbl}$ GATA mice, $P H I L$ mice not only showed decreases in airway remodeling, but less mucous production and decreased airway hyperresponsiveness as well. Though the observations from $\Delta \mathrm{dbl}$ GATA and PHIL mice were not identical, this pair of studies powerfully suggested that eosinophils are indeed active offenders in animal models of allergic airway inflammation. Further studies have been performed in $\Delta$ dbl GATA mice suggesting that differences in the background strains of the experimental animals may be partially responsible for the differences in phenotype. Walsh and colleagues [7] studied the phenotype of $\Delta \mathrm{dbl} \mathrm{GATA}$ mice on a C57BL/6 background in an allergic airway disease model rather than the $\Delta$ dbl GATA BALB/c background reported in the earlier study. They found that $\Delta$ dbl GATA C57BL/6 mice showed both decreased airway hyperresponsiveness and decreased Th2 cytokine production in response to sensitization and challenge with ovalbumin. Significantly, adoptive transfer of eosinophils restored airway hyperresponsiveness and Th2 inflammation in these animals. Eotaxin-1 also appeared necessary to induce T-cell recruitment to the airways and airway hyperresponsiveness, as intranasal administration of eotaxin-1 restored these responses in $\Delta \mathrm{dbl}$ GATA C57BL/6 mice independent of the presence of eosinophils. The modulated phenotype in asthma models of $\Delta \mathrm{dbl}$ GATA C57BL/6 mice and PHIL mice is depicted in figure 1.

Several subsequent animal studies have supported the general conclusion that eosinophils are a necessary active component of allergic airway disease. Fulkerson and colleagues [8] examined the effect of blocking eosinophil recruitment to the lung using knockout mice deficient in the eotaxin receptor CCR3, as well as knockout mice deficient in both eotaxin-1 and eotaxin-2. They compared the response to repeated challenge with intranasal Aspergillus fumigatus extract to that obtained in $\Delta \mathrm{dbl}$ GATA mice. Whether eosinophil recruitment was impaired by lack of eotaxin or by lack of eotaxin receptor, these mice had a reduction in mucous production. In addition, CCR3-deficient mice also had a decrease in the Th2 cytokines interleukin (IL)-4 and IL-13 present in homogenized lung specimens. Similarly, as with the ovalbumin challenge, $\Delta \mathrm{dbl}$ GATA mice also showed decreased mucous as well as decreased IL-4 production. In another study using $\Delta$ dbl GATA mice that had inducible overexpression of IL-13, these investigators found that the leukocyte recruitment to the lung, the mucous cell metaplasia, and the airway remodeling attributable to IL-13 overexpression was partially dependent on eosinophils [9].

Jacobsen et al. [10] further characterized the responses of PHIL mice to ovalbumin sensitization and challenge in a series of experiments showing that eosinophils are not only effector cells but that they have an active immunoregulatory role in allergic airway inflammation. They 
Fig. 1. Attenuated allergic inflammation in eosinophil-deficient mice. In the ovalbumin airway antigen challenge model, eosinophil-deficient $\Delta \mathrm{dbl}$ GATA mice and PHIL mice experienced significant downregulation of airway hyperresponsiveness (AHR) and remodeling as compared to wild-type mice.
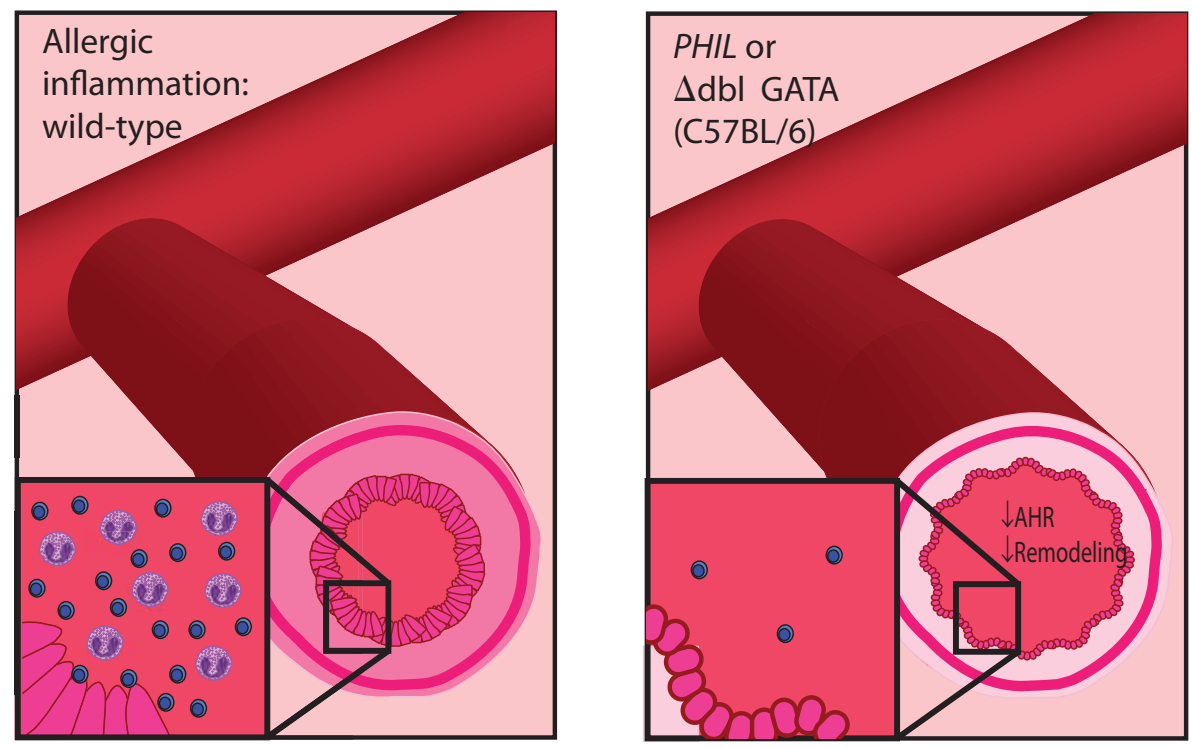

found that ovalbumin-primed and -challenged PHIL mice have decreased Th2 cytokine production in the lungs as well as decreased accumulation of lymphocytes to the airways, to the pulmonary parenchyma, and to draining lymph nodes. In a series of elegant adoptive transfer experiments using a combination of intravenous administration of OT-II T cells, which express T-cell receptor specific to ovalbumin, and intratracheal administration of eosinophils, they demonstrated that OT-II cells alone were insufficient to restore lymphocyte accumulation in the respiratory system of ovalbumin-challenged PHIL mice. Rather, the administration of intratracheal eosinophils was an absolute requirement to promote the accumulation of lymphocyte subsets and the production of the Th2 cytokines IL-5 and IL-13 in the lungs.

IL-33 has recently been identified as a potential key contributor to the multifaceted effects of eosinophils in allergic airway inflammation [11]. In mice deficient in a component of the IL-33 receptor, adoptive transfer of wild-type eosinophils to mice who were subsequently stimulated with IL-33 induced airway inflammation [11]. While the importance of IL-33 in allergic airway disease remains an ongoing field of investigation, this study provides additional key evidence showing the importance of eosinophils as an active inflammatory cell as opposed to a bystander cell.

Kanda and colleagues [12] reported that intratracheal adoptive transfer of activated eosinophils to wild-type recipient mice induced inflammatory cell accumulation to the airways and induced airway hyperresponsiveness.
When eosinophils were transferred to mice with severe combined immunodeficiency, inflammatory cell recruitment and airway hyperresponsiveness were still observed, indicating that eosinophils exerted an effect independent of lymphocytes. Surprisingly, they also found that the effect of eosinophils was dependent on interferon (IFN)- $\gamma$ from the donor eosinophils, as eosinophils that were deficient in IFN- $\gamma$ did not induce airway hyperresponsiveness.

Through the use of animal models deficient in eosinophils and by taking advantage of the adoptive transfer of eosinophils, evidence has now emerged that convincingly argues that eosinophils are a necessary component of allergic inflammation.

\section{Eosinophils in Human Allergic Airway Disease}

Eosinophil counts in the blood and in the lungs have long been correlated with disease severity in human asthma, but whether they are truly active in disease pathogenesis has been an ongoing point of controversy [13]. Cationic granule proteins released from eosinophils cause bronchoreactivity and airway remodeling in experimental models [14-16], and as emphasized throughout this review, a wealth of experimental evidence suggests that eosinophils have a complex immunoregulatory function in allergic disease. From a clinical perspective, a series of studies of eosinophil depletion in human subjects with monoclonal antibody against IL-5 has added depth to the 
argument that eosinophils have an active, non-bystander role in pulmonary disease. IL-5 has a central role in eosinophil differentiation, bone marrow egress, and survival [17]. The first randomized, double-blinded, placebocontrolled study of eosinophil depletion with anti-IL-5 therapy in asthma actually supported the hypothesis that eosinophils act only as non-active markers of inflammation in asthma [18]. The patients studied in this trial had a clinical diagnosis of asthma with persistent symptoms despite the use of inhaled corticosteroids. While blood and sputum eosinophils were reduced after treatment with anti-IL-5 therapy, this study failed to find any statistically significant improvement in clinical outcomes with a course of therapy with a monoclonal antibody against IL-5. However, because human asthma is a heterogeneous disease that represents a final common phenotype to several pathways of airway inflammation, 2 subsequent studies sought to study the effect of eosinophil depletion with anti-IL-5 therapy in subjects with asthma characterized by eosinophilic inflammation $[19,20]$. In both studies, subjects with refractory asthma were selected based on the finding of eosinophils in their sputum. Unlike the earlier trial in unselected patients, both of these trials did indeed show an improvement in clinical variables with treatment with anti-IL-5 monoclonal antibody. From a mechanistic perspective, these studies strongly suggest that, at least in selected forms of asthma, eosinophils have an active role in disease pathogenesis and not just a bystander role as previously suggested. Eosinophil depletion with anti-IL-5 therapy has also proven effective in clinical trials studying patients with Churg-Strauss syndrome and hypereosinophilic syndrome, both of which can feature prominent components of pulmonary eosinophilic infiltration [21,22]. Because the target of anti-IL-5 therapy is specific to eosinophils, these clinical studies have provided important insight into the contribution of eosinophils to human disease and support the mechanistic hypothesis that eosinophils are true offenders in allergic airway disease.

\section{Immunoregulation by Eosinophils in Allergic Airway Disease}

As previously written, eosinophils have been increasingly recognized as having immunoregulatory function, with multiple lines of evidence from models of allergic airway inflammation [23]. Human eosinophils have been revealed as having preformed stores of multiple Th1 and Th2 cytokines that are available for rapid release [24]. The presence of these pools of cytokines provides a potential mechanism to explain the multifaceted immunoregulation that eosinophils have demonstrated in a growing number of published studies. Of particular interest are novel findings that IL-4 in eosinophil granules is bound to IL- 4 receptor $\alpha$ chain and that this complex is mobilized into secretory vesicles upon eotaxin stimulation of eosinophils [25]. Chen et al. [26] showed in an ovalbumin murine allergic inflammation model that eosinophils are the dominant source of IL-4, providing strong evidence for the immunoregulatory importance of eosinophils in Th2 allergic airway inflammation. Eosinophils have been demonstrated to produce IL- 4 and IL-5 in a ragweed antigen challenge model as well, providing yet further support for eosinophils as orchestrators of Th2 polarization [27]. While the above data are of particular interest in addressing the issue of the active role of eosinophils specifically in pulmonary allergic inflammation, a large quantity of data has accumulated that demonstrate protean immunoregulation of Th2 immunity in general by eosinophils [28].

There is also increasing evidence that eosinophils have important roles as 'professional' major histocompatibility complex (MHC) class-II-restricted antigen-presenting cells (APCs) $[23,29]$. Much of this evidence comes from the study of eosinophils in models of allergic pulmonary inflammation and from observations made in human disease. The increasing recognition of APC capability of eosinophils in pulmonary inflammation suggests that eosinophils are active immune cells in the respiratory system rather than bystanders. While unstimulated peripheral blood eosinophils do not express MHC class II, airway eosinophils from several pulmonary disease states have been noted to have the requisite MHC class II expression necessary for antigen presentation [30-32]. Sputum eosinophils in asthma and bronchoalveolar lavage eosinophils in chronic eosinophilic pneumonia have both been observed to have upregulation of MHC class II $[30,31]$. In addition, eosinophils recovered from bronchoalveolar lavage from allergic subjects subjected to bronchoscopic segmental allergen challenge express increased MHC class II [32]. In murine models of allergic airway inflammation, airway eosinophils not only express increased MHC class II but also increased levels of the costimulatory proteins CD80 and CD86 [33-35]. Eosinophils have now been demonstrated in murine studies to functionally present antigen in models of allergic airway inflammation $[34,36]$. Our laboratory has found that eosinophils can be considered 'professional' APCs, with the ability to stimulate naïve T cells [36]. In this set of ex- 
periments, ovalbumin-loaded eosinophils intratracheally administered to naïve mice who received injections of ovalbumin-specific CD4+ T cells induced CD69 upregulation, proliferation, and IL-4 production in the antigenspecific $\mathrm{T}$ cells [36]. While the question of the relative importance of eosinophil APC function in human asthma remains open, it has now been unequivocally established in murine models and in vitro studies using human cells that eosinophils have the capability to perform APC functions [29].

\section{Eosinophils in Pulmonary Immunity}

Recent evidence indicates that eosinophils may have a protective role in the defense against certain respiratory infections rather than only a pathogenic role mediated by release of preformed granule contents. Human eosinophils express several Toll-like receptors (TLRs), an observation suggesting that eosinophils may have a more important role in the host defense against a variety of organisms than previously believed [37,38]. Stimulation of eosinophils with TLR7 ligands causes them to assume an activated phenotype, with increased expression of cell surface adhesion molecules, prolonged survival, and increased production of superoxide [37]. Stimulation with ligands of TLR 2 and TLR 5 has also been observed to activate human eosinophils [38]. The array of receptors expressed by eosinophils for pathogen-associated molecular patterns, including the TLR family, has recently been reviewed elsewhere [39].

As noted in previous reviews [40,41], though the influx of eosinophils seen in respiratory syncytial virus (RSV) infection has long been thought to be exclusively pathogenic, eosinophilia appears to have a potentially protective role in models of RSV infection. Human eosinophils have been shown to inhibit the growth of RSV in culture, with inhibition of eosinophil ribonuclease reversing the antiviral properties of eosinophils [42]. In addition, the same study demonstrated that recombinant human eosinophil-derived neurotoxin, the ribonuclease found in eosinophil granules, also inhibited viral replication [42]. Others have demonstrated that eosinophils can inhibit the spread of RSV to uninfected cells in cultures of epithelial cells [43]. Phipps et al. [44] observed that eosinophils promote clearance of RSV in murine infection through a TLR7-dependent mechanism. IL-5 transgenic mice, which have high numbers of circulating eosinophils, were found to have enhanced clearance of RSV. They observed that signaling occurred through MyD88, as transfer of MyD88-deficient eosinophils to infected mice did not promote viral clearance, as opposed to transfer of wild-type eosinophils, which did promote viral clearance. Eosinophils have additionally been found to act as APCs of viral antigens to T cells [45]. Human eosinophils are able to stimulate proliferation and IFN- $\gamma$ production of T cells specific to an RSV antigen [45].

While most of the evidence supporting a role for eosinophils in anti-viral immunity is from studies of RSV, additional evidence suggesting a role for eosinophils in viral immunity comes from a study by Adamko et al. [46] of guinea pigs infected with parainfluenza. They found that animals that were sensitized with ovalbumin prior to infection with parainfluenza had a reduction in viral content in the lungs that was reversed when eosinophils were depleted with anti-IL-5 antibody [46].

Eosinophils may have a role in pulmonary immunity against bacterial infections as well, given recent in vitro findings showing the ability of eosinophils to participate in bacterial killing. Eosinophils have been observed to secrete granule contents in response to in vitro exposure to several species of Gram-positive and Gram-negative bacteria and exhibit chemotaxis to several bacterial species as well [47]. One recent study found that eosinophils release mitochondrial DNA and granule content in a catapult-like fashion in response to stimulation with lipopolysaccharide [48]. Furthermore, in co-culture with Escherichia coli, bacterial killing occurred in a DNA-dependent manner. In another study, mouse eosinophils were found to kill Pseudomonas aeruginosa in vitro [49]. While both of these studies included in vivo experiments demonstrating bacterial clearance, neither used respiratory infection as an experimental model. However, one may speculate that eosinophils may play a role in clearance of certain respiratory infections, given that Gramnegative bacteria, though not the most common perpetrators, are implicated in pulmonary infectious processes.

Eosinophils have also been studied in vitro with respect to their ability to kill mycobacterial organisms, another type of bacteria with a propensity for pulmonary infection [50]. Driss et al. [50] reported that human eosinophils exhibit chemotaxis toward Mycobacterium bovis and have increased reactive oxygen species production, eosinophil cationic protein release, and tumor necrosis factor- $\alpha$ secretion when incubated with mycobacteria. Furthermore, they demonstrated that eosinophils respond to mycobacteria in a TLR2-dependent manner and kill mycobacteria through the action of $\alpha$ defensins. Interestingly, a prior report describes that 
TLR2-deficient mice have a reduction in the characteristic eosinophil accumulation seen in pleural space infection with M. bovis [51]. It has also been observed that human eosinophils upregulate expression of $\gamma \delta$ T-cell receptor when exposed to mycobacterial antigens and that they have $\gamma \delta$ T-cell receptor-dependent reactive oxygen species generation and release of granule contents and cytokines in response to mycobacteria [52].

Though the story remains incomplete, the above data provide a strong argument that eosinophils have important function in pulmonary immunity against specific viral and bacterial pathogens.

\section{Conclusion}

Continually increasing evidence has supported a new conception of eosinophils as multifaceted immune cells with complex interactions with other immune cells and their local environment. The role of eosinophils in allergic airway disease as being fundamentally active in nature has been brought into sharp relief by animal models of genetic eosinophil depletion, human studies of eosinophil depletion with monoclonal antibody against IL-5, and a series of investigations that establish eosinophils as immunoregulatory cells with key roles in orchestrating Th2 airway inflammation and in functioning as APCs. In pulmonary immunity, several lines of evidence suggest that eosinophils have the ability to promote clearance of certain viral, bacterial, and mycobacterial organisms. In short, the question posed by the title of this review can now be definitively answered, albeit with an important modification. Eosinophils are neither offenders nor bystanders in allergic airway disease and pulmonary immunity. They are active, integral immune cells that have myriad effects on the respiratory system in allergic inflammation and infection.

\section{Acknowledgements}

This work was supported by National Institutes of Health R01 grants AI051645 and AI020241 (to P.F.W.) and F32 AI081513 (to P.A.).

\section{References}

1 Spry CJF: Eosinophils: A Comprehensive Review and Guide to the Scientific and Medical Literature. Oxford, Oxford University Press, 1988.

-2 Lee JJ, Jacobsen EA, McGarry MP, Schleimer RP, Lee NA: Eosinophils in health and disease: the LIAR hypothesis. Clin Exp Allergy 2010;40:563-575.

-3 Humbles AA, Lloyd CM, McMillan SJ, Friend DS, Xanthou G, McKenna EE, Ghiran S, Gerard NP, Yu C, Orkin SH, Gerard C: A critical role for eosinophils in allergic airways remodeling. Science 2004;305:17761779.

4 Lee JJ, Dimina D, Macias MP, Ochkur SI, McGarry MP, O’Neill KR, Protheroe C, Pero $\mathrm{R}$, Nguyen T, Cormier SA, Lenkiewicz E, Colbert D, Rinaldi L, Ackerman SJ, Irvin CG, Lee NA: Defining a link with asthma in mice congenitally deficient in eosinophils. Science 2004;305:1773-1776.

$\checkmark 5 \mathrm{Yu}$ C, Cantor AB, Yang H, Browne C, Wells RA, Fujiwara Y, Orkin SH: Targeted deletion of a high-affinity GATA-binding site in the GATA-1 promoter leads to selective loss of the eosinophil lineage in vivo. J Exp Med 2002;195:1387-1395.

6 Wills-Karp M, Karp CL: Biomedicine. Eosinophils in asthma: remodeling a tangled tale. Science 2004;305:1726-1729.
7 Walsh ER, Sahu N, Kearley J, Benjamin E, Kang BH, Humbles A, August A: Strain-specific requirement for eosinophils in the recruitment of $\mathrm{T}$ cells to the lung during the development of allergic asthma. J Exp Med 2008;205:1285-1292.

-8 Fulkerson PC, Fischetti CA, McBride ML, Hassman LM, Hogan SP, Rothenberg ME: A central regulatory role for eosinophils and the eotaxin/CCR3 axis in chronic experimental allergic airway inflammation. Proc Natl Acad Sci USA 2006;103:16418-16423.

$\checkmark 9$ Fulkerson PC, Fischetti CA, Rothenberg ME: Eosinophils and CCR3 regulate interleukin-13 transgene-induced pulmonary remodeling. Am J Pathol 2006;169:2117-2126.

10 Jacobsen EA, Ochkur SI, Pero RS, Taranova AG, Protheroe CA, Colbert DC, Lee NA, Lee JE: Allergic pulmonary inflammation in mice is dependent on eosinophil-induced recruitment of effector T cells. J Exp Med 2008; 205:699-710.

11 Kurowska-Stolarska M, Stolarski B, Kewin P, Murphy G, Corrigan CJ, Ying S, Pitman N, Mirchandani A, Rana B, van Rooijen N, Shepherd M, McSharry C, McInnes IB, Xu D, Liew FY: IL-33 amplifies the polarization of alternatively activated macrophages that contribute to airway inflammation. J Immunol 2009;183:6469-6477.
12 Kanda A, Driss V, Hornez N, Abdallah M, Roumier T, Abboud G, Legrand F, Staumont-Salle D, Queant S, Bertout J, Fleury S, Remy P, Papin JP, Julia V, Capron M, Dombrowicz D: Eosinophil-derived IFN-gamma induces airway hyperresponsiveness and lung inflammation in the absence of lymphocytes. J Allergy Clin Immunol 2009;124: 573-582, e.1-9.

13 Bousquet J, Chanez P, Lacoste JY, Barneon G, Ghavanian N, Enander I, Venge P, Ahlstedt S, Simony-Lafontaine J, Godard P, et al: Eosinophilic inflammation in asthma. N Engl J Med 1990;323:1033-1039.

14 Gundel RH, Letts LG, Gleich GJ: Human eosinophil major basic protein induces airway constriction and airway hyperresponsiveness in primates. J Clin Invest 1991;87:14701473.

15 Venge P: The eosinophil and airway remodelling in asthma. Clin Respir J 2010;4(suppl 1):15-19.

16 Pegorier S, Wagner LA, Gleich GJ, Pretolani M: Eosinophil-derived cationic proteins activate the synthesis of remodeling factors by airway epithelial cells. J Immunol 2006;177: 4861-4869.

$\checkmark 17$ Rothenberg ME, Hogan SP: The eosinophil. Annu Rev Immunol 2006;24:147-174. 
18 Flood-Page P, Swenson C, Faiferman I, Matthews J, Williams M, Brannick L, Robinson D, Wenzel S, Busse W, Hansel TT, Barnes NC: A study to evaluate safety and efficacy of mepolizumab in patients with moderate persistent asthma. Am J Respir Crit Care Med 2007;176:1062-1071.

- 19 Haldar P, Brightling CE, Hargadon B, Gupta S, Monteiro W, Sousa A, Marshall RP, Bradding P, Green RH, Wardlaw AJ, Pavord ID: Mepolizumab and exacerbations of refractory eosinophilic asthma. N Engl J Med 2009;360:973-984.

-20 Nair P, Pizzichini MM, Kjarsgaard M, Inman MD, Efthimiadis A, Pizzichini E, Hargreave FE, O’Byrne PM: Mepolizumab for prednisone-dependent asthma with sputum eosinophilia. N Engl J Med 2009;360:985993.

-21 Kim S, Marigowda G, Oren E, Israel E, Wechsler ME: Mepolizumab as a steroidsparing treatment option in patients with Churg-Strauss syndrome. J Allergy Clin Immunol 2010;125:1336-1343.

-22 Rothenberg ME, Klion AD, Roufosse FE, Kahn JE, Weller PF, Simon HU, Schwartz LB, Rosenwasser LJ, Ring J, Griffin EF, Haig AE, Frewer PI, Parkin JM, Gleich GJ: Treatment of patients with the hypereosinophilic syndrome with mepolizumab. N Engl J Med 2008;358:1215-1228

-23 Akuthota P, Wang HB, Spencer LA, Weller PF: Immunoregulatory roles of eosinophils: a new look at a familiar cell. Clin Exp Allergy 2008;38:1254-1263.

-24 Spencer LA, Szela CT, Perez SA, Kirchhoffer CL, Neves JS, Radke AL, Weller PF: Human eosinophils constitutively express multiple Th1, Th2, and immunoregulatory cytokines that are secreted rapidly and differentially. J Leukoc Biol 2009;85:117-123.

-25 Spencer LA, Melo RC, Perez SA, Bafford SP, Dvorak AM, Weller PF: Cytokine receptormediated trafficking of preformed IL-4 in eosinophils identifies an innate immune mechanism of cytokine secretion. Proc Natl Acad Sci USA 2006;103:3333-3338.

-26 Chen L, Grabowski KA, Xin JP, Coleman J, Huang Z, Espiritu B, Alkan S, Xie HB, Zhu Y, White FA, Clancy J Jr, Huang H: IL-4 induces differentiation and expansion of Th2 cytokine-producing eosinophils. J Immunol 2004;172:2059-2066.

-27 Justice JP, Borchers MT, Lee JJ, Rowan WH, Shibata Y, Van Scott MR: Ragweed-induced expression of GATA-3, IL-4, and IL- 5 by eosinophils in the lungs of allergic C57BL/6J mice. Am J Physiol Lung Cell Mol Physiol 2002;282:L302-L309.
8 Spencer LA, Weller PF: Eosinophils and Th2 immunity: contemporary insights. Immunol Cell Biol 2010;88:250-256.

29 Akuthota P, Wang H, Weller PF: Eosinophils as antigen-presenting cells in allergic upper airway disease. Curr Opin Allergy Clin Immunol 2010;10:14-19.

30 Beninati W, Derdak S, Dixon PF, Grider DJ, Strollo DC, Hensley RE, Lucey DR: Pulmonary eosinophils express HLA-DR in chronic eosinophilic pneumonia. J Allergy Clin Immunol 1993;92:442-449.

- 31 Hansel TT, Braunstein JB, Walker C, Blaser K, Bruijnzeel PL, Virchow JC Jr, Virchow C Sr: Sputum eosinophils from asthmatics express ICAM-1 and HLA-DR. Clin Exp Immunol 1991;86:271-277.

32 Sedgwick JB, Calhoun WJ, Vrtis RF, Bates ME, McAllister PK, Busse WW: Comparison of airway and blood eosinophil function after in vivo antigen challenge. J Immunol 1992;149:3710-3718.

33 MacKenzie JR, Mattes J, Dent LA, Foster PS: Eosinophils promote allergic disease of the lung by regulating CD4(+) Th2 lymphocyte function. J Immunol 2001;167:3146-3155.

34 Shi HZ, Humbles A, Gerard C, Jin Z, Weller PF: Lymph node trafficking and antigen presentation by endobronchial eosinophils. J Clin Invest 2000;105:945-953.

-35 Tamura N, Ishii N, Nakazawa M, Nagoya M, Yoshinari M, Amano T, Nakazima H, Minami M: Requirement of CD80 and CD86 molecules for antigen presentation by eosinophils. Scand J Immunol 1996;44:229-238.

36 Wang HB, Ghiran I, Matthaei K, Weller PF: Airway eosinophils: allergic inflammation recruited professional antigen-presenting cells. J Immunol 2007;179:7585-7592.

37 Nagase H, Okugawa S, Ota Y, Yamaguchi M, Tomizawa H, Matsushima K, Ohta K, Yamamoto K, Hirai K: Expression and function of Toll-like receptors in eosinophils: activation by Toll-like receptor 7 ligand. J Immunol 2003;171:3977-3982.

38 Wong CK, Cheung PF, Ip WK, Lam CW: Intracellular signaling mechanisms regulating Toll-like receptor-mediated activation of eosinophils. Am J Respir Cell Mol Biol 2007;37: 85-96.

39 Shamri R, Xenakis JJ, Spencer LA: Eosinophils in innate immunity: an evolving story. Cell Tissue Res 2011;343:57-83.

40 Rosenberg HF, Dyer KD, Domachowske JB: Eosinophils and their interactions with respiratory virus pathogens. Immunol Res 2009;43:128-137.

41 Rosenberg HF, Dyer KD, Domachowske JB: Respiratory viruses and eosinophils: exploring the connections. Antiviral Res 2009;83: $1-9$.
42 Domachowske JB, Dyer KD, Bonville CA, Rosenberg HF: Recombinant human eosinophil-derived neurotoxin/RNase 2 functions as an effective antiviral agent against respiratory syncytial virus. J Infect Dis 1998;177: 1458-1464.

43 Soukup JM, Becker S: Role of monocytes and eosinophils in human respiratory syncytial virus infection in vitro. Clin Immunol 2003; 107:178-185.

44 Phipps S, Lam CE, Mahalingam S, Newhouse M, Ramirez R, Rosenberg HF, Foster PS, Matthaei KI: Eosinophils contribute to innate antiviral immunity and promote clearance of respiratory syncytial virus. Blood 2007;110:1578-1586.

45 Handzel ZT, Busse WW, Sedgwick JB, Vrtis R, Lee WM, Kelly EA, Gern JE: Eosinophils bind rhinovirus and activate virus-specific $\mathrm{T}$ cells. J Immunol 1998;160:1279-1284.

46 Adamko DJ, Yost BL, Gleich GJ, Fryer AD, Jacoby DB: Ovalbumin sensitization changes the inflammatory response to subsequent parainfluenza infection. Eosinophils mediate airway hyperresponsiveness, $\mathrm{m}(2)$ muscarinic receptor dysfunction, and antiviral effects. J Exp Med 1999;190:1465-1478.

47 Svensson L, Wenneras C: Human eosinophils selectively recognize and become activated by bacteria belonging to different taxonomic groups. Microbes Infect 2005;7:720728.

48 Yousefi S, Gold JA, Andina N, Lee JJ, Kelly AM, Kozlowski E, Schmid I, Straumann A, Reichenbach J, Gleich GJ, Simon HU: Catapult-like release of mitochondrial DNA by eosinophils contributes to antibacterial defense. Nat Med 2008;14:949-953.

49 Linch SN, Kelly AM, Danielson ET, Pero R, Lee JJ, Gold JA: Mouse eosinophils possess potent antibacterial properties in vivo. Infect Immun 2009;77:4976-4982.

50 Driss V, Legrand F, Hermann E, Loiseau S, Guerardel Y, Kremer L, Adam E, Woerly G, Dombrowicz D, Capron M: TLR2-dependent eosinophil interactions with mycobacteria: role of alpha-defensins. Blood 2009; 113:3235-3244.

51 D’Avila H, Almeida PE, Roque NR, CastroFaria-Neto HC, Bozza PT: Toll-like receptor2-mediated C-C chemokine receptor 3 and eotaxin-driven eosinophil influx induced by Mycobacterium bovis BCG pleurisy. Infect Immun 2007;75:1507-1511.

-52 Legrand F, Driss V, Woerly G, Loiseau S, Hermann E, Fournie JJ, Heliot L, Mattot V, Soncin F, Gougeon ML, Dombrowicz D, Capron M: A functional gammadeltaTCR/ CD3 complex distinct from gammadeltaT cells is expressed by human eosinophils. PLoS One 2009;4:e5926. 